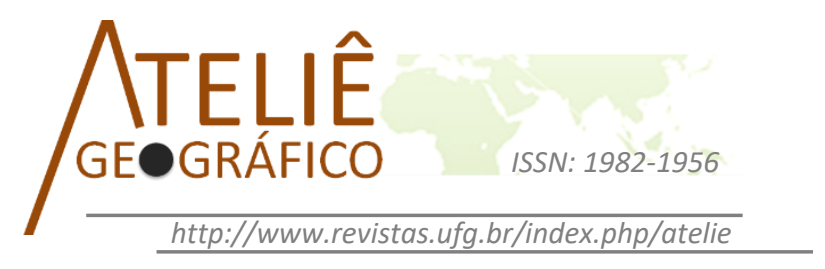

\title{
A ferrovia como via de integração nacional: um discurso sobre a unidade territorial
}

\author{
The railroad as a way of national integration: a discourse on \\ territorial unity \\ El ferrocarril como vía de integración nacional: un discurso \\ sobre la unidad territorial
}

\author{
Marco Túlio Martins \\ Universidade Estadual de Goiás \\ marcogeografia2008@yahoo.com.br
}
Rita de Cássia Martins de Souza
Universidade Federal de Uberlândia
ritacmsou@gmail.com

\begin{abstract}
Resumo
Este trabalho intitulado A ferrovia como via de integração nacional: um discurso sobre a unidade territorial tem como objetivo central a análise da materialidade geográfica projetada a partir dos discursos dos geopolíticos militares, no caso, o historiador e geopolítico brasileiro Nelson Werneck Sodré em consonância com o discurso de Mário Travassos. Foi abordada uma perspectiva geopolítica recorrente nas obras e nos discursos promulgados pelos militares, qual seja: a integração nacional e a formação do mercado interno; a ferrovia e a integração territorial. A análise está envolta da perspectiva de formação do território brasileiro, constituindo uma das perspectivas teórico-metodológica do pensamento geográfico: o discurso geográfico como forma de projeção da materialidade territorial de um Estado.
\end{abstract}

Palavras-Chave: Pensamento Geográfico; Unidade Territorial brasileira; geopolítica brasileira; Nelson Werneck Sodré.

\begin{abstract}
This paper is entitled "The railroad as a way of national integration: a discourse on territorial unity" has as main aim the analysis of the geographic materiality projected from the discourses of military geopolitics, in this case, the Brazilian historian and geopolitical Nelson Werneck Sodré in line with the speech of Mario Travassos. A recurrent geopolitical perspective was addressed in the works and discourses promulgated by the military, namely: national integration and the formation of the
\end{abstract}


internal market; the railways and territorial integration. The analysis is around of the perspective of formation of the Brazilian territory, constituting one of the theoreticalmethodological perspectives of the geographic thought: the geographic discourse as a form of projection of the territorial materiality of a State.

Keywords: Geographic Thinking; Brazilian Territorial Unit; Brazilian geopolitics; Nelson Werneck Sodré.

\begin{abstract}
Resumen
Este trabajo titulado "El ferrocarril como vía de integración nacional: un discurso sobre la unidad territorial" tiene como objetivo central el análisis de la materialidad geográfica proyectada a partir de los discursos de los geopolíticos militares, en el caso, el historiador y geopolítico brasileño Nelson Werneck Sodré en consonancia con el discurso de Mário Travassos. Se abordó una perspectiva geopolítica recurrente en las obras y en los discursos promulgados por los militares, es decir: la integración nacional y la formación del mercado interior; el ferrocarril y la integración territorial. El análisis está envuelto en la perspectiva de formación del territorio brasileño, constituyendo una de las perspectivas teórico-metodológicas del pensamiento geográfico: el discurso geográfico como forma de proyección de la materialidad territorial de un Estado. Palabras Clave: Pensamiento Geográfico; Unidad Territorial brasileña; geopolítica brasileña; Nelson Werneck Sodré.
\end{abstract}

\title{
Introdução
}

A preocupação do Estado brasileiro com a imensidão de terras existentes e distantes do centro de poder econômico do país junto à dificuldade de administrá-las gerou, na primeira metade do século $\mathrm{XX}$, numerosos intelectuais partidários de um poder centralizado e de um executivo forte que formularam estudos geopolíticos, muitos deles baseados em teorias desenvolvidas na Europa. Alguns exemplos desses intelectuais geopolíticos são Mário Travassos (1935), Everardo Backheuser (1952), Teixeira de Freitas (1941) e Lysias Rodrigues (1947). (ANDRADE, 1993). A principal temática levantada por eles foi a questão da unidade territorial.

Segundo Costa (2008), não se pode falar de um pensamento geopolítico no Brasil, muito menos geográfico-político, naquele sentido de ser um produto "de um ambiente de reflexão acadêmico especificamente universitário". O que se apresentou no Brasil foi uma adaptação das teorias européias para a elaboração de uma geopolítica para o país (COSTA, 2008, p.180). Na análise de obras como as de Mário Travassos e Everardo Backheuser percebe-se perfeitamente tais adaptações.

Junto a isso, não foram os geógrafos de formação que produziram a geopolítica brasileira, consequentemente não foram eles "os seus principais comentaristas". Muito diferente da realidade européia, os estudos geopolíticos no Brasil "tiveram a hegemonia do pensamento militar e das suas instituições" (COSTA, 2008, 180).

Nesse sentido, a obra de Nelson Werneck Sodré - um militar "historiador" do século $\mathrm{XX}$ - nunca foi analisada como parte dessas produções geopolíticas ligadas às 
ideologias do Estado Getulista, muito menos naquilo que se refere ao discurso sobre as "vias de comunicação" no Brasil, acompanhando o discurso desenvolvido por Mário Travassos (1931).

As "vias de comunicação" refletem um sentido mais amplo do que simplesmente as "vias de transporte". Para além dos transportes, as aberturas, os caminhos naturais ou construídos pelo homem possibilitaram as trocas de ideias, a chegada do desenvolvimento econômico (como o Estado desejava) e a certeza da efetivação da unidade entre as regiões do território brasileiro.

Do século XVIII até o início do século XX o Estado brasileiro lutou para delimitar suas fronteiras internas, sobretudo na região da Bacia do Prata, onde conflitos como a Guerra do Paraguai agitaram um período da nossa história. No século XX, a expansão ferroviária argentina provocou uma reação brasileira tencionando ainda mais a rivalidade entre os dois maiores países sul-americanos. A disputa por áreas de influência como, por exemplo, Uruguai, Paraguai e Bolívia também foram alvos das práticas das classes dominantes no Brasil.

A geopolítica do Estado brasileiro após a Revolução de 1930 foi extremamente influenciada pelos intelectuais que elaboraram obras contendo uma "manipulação" de alguns conhecimentos geográficos que possibilitaram a "formulação de esquemas" que interessassem às "políticas de poder" (COSTA, 2008, p.179). Algumas dessas "políticas de poder", as territoriais, foram colocadas em prática pelo Estado: a Marcha para o Oeste, a criação de territórios federais e as políticas direcionadas à população. (ANDRADE, 1993).

Nelson Werneck Sodré foi um dos intelectuais do século XX, ligados ao Exército e também às instituições militares de ensino, que contribuiu para a formação da chamada geopolítica brasileira. Este artigo tem como objetivo central analisar algumas temáticas desenvolvidas na obra de Sodré, tais como, a integração regional por meio da instalação de uma malha ferroviária e as duas grandes bacias hidrográficas brasileiras que contribuíram para a unidade territorial do país, sendo estas, contribuições que necessariamente utilizaram-se da manipulação de conhecimentos geográficos para ligálos aos desejos do Estado, sobretudo, entre os anos de 1930-1945.

\section{A ferrovia como uma possibilidade de integração entre o interior e o litoral: segurança e integração territorial}

Nelson Werneck Sodré manifestou uma preocupação eminente durante todo o livro "Oeste" com a identidade nacional, porém não fixou sua atenção somente sobre esse tema, mas o ligou ao problema da unidade do território. A proposta de Sodré esteve focada, nessa obra, sobre a efetivação de um processo de desenvolvimento do país pelas vias férreas e na criação/ampliação do mercado interno. A preocupação do autor em relação à identidade nacional brasileira perpassa outras de suas produções com forte influência do pensamento autoritário da época. 
No início da década de 1930, a luta entre o poder central e os grupos regionais estava vinculada diretamente à questão da unidade e integração do território brasileiro. Neste contexto, a corrente do pensamento autoritário ganhou força. (FAUSTO, B, 2008).

Sob a égide desse pensamento foi projetada a modernização do país, num processo que foi denominado de modernização conservadora alimentado pelas classes dominantes do país. Barrington Moore Junior (1967), analisando as revoluções burguesas na Alemanha e no Japão na transição das economias pré-industriais para as economias industriais (capitalistas) elaborou o conceito de modernização conservadora. (MORRE JUNIOR, 1967).

Moore Junior demonstrou três caminhos que podem ser seguidos no mundo moderno. O segundo caminho, ou a segunda via, o autor denomina de capitalista e reacionária. $\mathrm{O}$ processo de modernização que ocorreu nos países que seguiram esta via foram enquadrados no desenvolvimento capitalista com características autocráticas e autoritárias, tal como no caso brasileiro. (MORRE JUNIOR, 1967, p.477).

Influenciado pelo pensamento autoritário, sobretudo por Oliveira Vianna, Sodré, no Oeste, trabalhou com a unidade e a integração do território brasileiro e a necessidade de instalação de objetos técnicos, como a malha ferroviária, a fim de garantir um discurso que sustentasse a projeção do Estado no processo integração do território.

A extensão territorial brasileira e as diferenças regionais eram as grandes preocupações dos estudos geopolíticos. Assim,

A unidade nacional passa a ser questão de extrema relevância e a centralização política ganha grande destaque, tornando-se tema de debates nacionais. Neste contexto, a divisão regional, já analisada por Oliveira Vianna, desde seu primeiro trabalho, desperta grande interesse e, talvez, isto tenha levado a uma leitura tão intensa de suas obras neste período [décadas de 1920 e 1930]. (ANSELMO, 1995, p.34).

Um dos grandes problemas do Brasil no que diz respeito à consolidação e efetivação da unidade territorial são as distâncias. A imensidão territorial sempre ocupou o front da preocupação do Estado no sentido de manter a extensão dessas terras pertencentes ao Brasil. Essa preocupação está ligada à antiga ideia geopolítica de que:

(...) a grande extensão territorial só se torna uma vantagem política e econômica quando associada a ocupação e povoamento adequados, ao mesmo tempo que o poder central, bem localizado, possa estabelecer relações de coesão eficazes no todo territorial. (COSTA, 2008, p.190).

O discurso geopolítico elaborado pelos intelectuais entre os anos de 1930 e 1945 contribuiu no sentido de projetar para o país a condição necessária para levá-lo ao processo de industrialização defendido e colocado em prática pelo Estado varguista. A defesa da 
construção das "vias de comunicação" no território, incluindo a construção de uma malha ferroviária para o Brasil aparece intrincada nesse discurso.

\section{O discurso geopolítico e geoestratégico sobre a ferrovia: Nelson Werneck Sodré, Mário Travassos e Golbery de Couto e Silva}

O projeto de Brasil presente na obra de Nelson Werneck Sodré no que diz respeito à questão da unidade territorial é um diálogo direto com as propostas de Mário Travassos. Nosso autor além de "revisitar" e enquadrar as teorias desse geopolítico às suas, segue a mesma base teórica de Travassos: Ratzel e Mackinder ${ }^{1}$.

Travassos foi um influente geopolítico militar brasileiro do início do século XX. Participou da Força expedicionária brasileira na Segunda Guerra Mundial, foi o primeiro comandante da Academia Militar das Agulhas Negras (AMAN) e também participou da Comissão que demarcou a capital Brasília no interior do território (1940-1950).

As obras Panorama do Segundo Império (1939) e Oeste (1941) de Nelson Werneck Sodré apresentam um diálogo direto com uma das principais obras de Mário Travassos, qual seja, Projeção Continental do Brasil (1931). Esses discursos, provenientes das instituições militares, só reforçam aquilo que Costa (2008) já destacou: "os estudos geopolíticos no Brasil tiveram a hegemonia do pensamento militar e das suas instituições".

Mário Travassos apresentou o território brasileiro como uma imensidão de possibilidades - possibilidades viatorias -, tanto no que diz respeito ao econômico como também ao político.

O fato decisivo, quando se olha para o conjunto do território brasileiro, engastado na massa continental sul-americana, reside nas notáveis possibilidades viatorias, já em franca manifestação pratica, que se traduzem, quer na neutralização do poder concentrico da bacia platina, quer na força de atração do Amazonas, quer na capacidade coordenadora do litoral atlântico em relação a ambas essas altas manifestações de potencial econômico e político que o Brasil tem em suas mãos (TRAVASSOS, 1931, p.109-110).

Esse militar também colocou em destaque o problema das distâncias territoriais entre as diferentes regiões brasileiras. No seu discurso, as comunicações que deveriam ser

\footnotetext{
1 "No campo intelectual, a geopolítica de Travassos sofreu uma influência determinante de Mackinder, com sua teoria do poder terrestre. Essa teoria foi reelaborada e aplicada de forma criadora às condições peculiares do continente sul-americano, com o planalto boliviano assumindo o papel de área chave com importância análoga à do "heartland" euroasiático. Para Travassos, o controle da Bolívia, região-pivô do continente, outorgaria ao Brasil o domínio político econômico sulamericano" (MELLO, 1987, p.73).
} 
viabilizadas entre essas regiões foram tratadas como um problema essencialmente geográfico, tal como Nelson Werneck Sodré abordou.

Essa característica decorre diretamente de que os fatos humanos, apesar dos crescentes recursos à disposição do homem, assentam, sobre fatos fundamentalmente geográficos, as possibilidades de atuação deste como agente modificador dos fatos naturais. (TRAVASSOS, 1931, p.151).

O Grande problema do Oeste é o das distancias. Elas se colocam, entre os pontos em que a civilização construiu alguma cousa, como hiatos enormes, a deprimir os homens, a tornar impossível o contacto das populações, que faz forte uma comunidade e lhe dá a consciência coletiva indispensável às organizações humanas. (SODRÉ, 1941, p.21).

A obra de Nelson Werneck Sodré apresentou como principal temática a relação interior-litoral e a importância da posição geoestratégica entre as bacias do Prata e a Amazônica. A obra de Travassos (1931) apresentou essa mesma característica: Atlântico vs Pacífico e Prata vs Amazonas.

Os olhares desses intelectuais geopolíticos militares na década de 1930 sobre essas "regiões" brasileiras tinham um objetivo final geoestratégico. Tanto Mário Travassos preocupado com as regiões ligadas ao Atlântico e ao Pacífico como Sodré discutindo a região oeste do país e a sua ligação com o litoral propunham as possibilidades estratégicas de comunicação entre essas regiões do país. Para isso, objetos técnicos (Ferrovias, Hidrovias, Cidades, etc) deveriam ser construídos no território e conduzir também os chamados "caminhos naturais" a uma utilização econômica.

Todas as propostas do autor, em especial as referentes a uma necessária estratégia de comunicações para o pais, giram em torno da influência brasileira na porção ocidental do continente, com repercussões nas áreas de contato ao sul (Uruguai) e ao norte (limites setentrionais da Amazônia). Daí a sua especial atenção para as vias terrestres de articulação: entre Santa Cruz de La Sierra e o porto de Santos (ferrovia Noroeste do Brasil), a Madeira-Mamoré, as pontes Brasil-Paraguai e as transcontinentais orientadas segundo os paralelos. Particularmente a ligação com Santa Cruz, ao lado da melhoria das vias navegáveis amazônicas, constitui para ele a possibilidade de o país cumprir o seu "destino geopolítico". Finalmente, e fazendo eco à geopolítica do período, Travassos defende com veemência o movimento de integração nacional em direção ao oeste. (COSTA, 2008, p.198).

A principal aproximação entre os discursos e as projeções de Nelson Werneck Sodré e Mário Travassos se estabelece na articulação geoestratégica entre os territórios 
sul-americanos. Travassos parte de uma "descrição"2 minuciosa das condições geográficas do continente e do território brasileiro para fazer suas proposições geopolíticas ao continente sul-americano. Distinguindo dessa exata "descrição", Sodré apresentou uma preocupação mais centrada na articulação do território brasileiro em si, sobretudo, no papel desempenhado por cada região, entretanto, não excluindo a importância e a necessidade de se projetar a base de comunicações entre os países vizinhos.

Nelson Werneck Sodré utilizou do discurso de Mário Travassos para compor sua análise sobre o papel desempenhado pelo estado do Mato Grosso na constituição da unidade brasileira, ou seja, a expressão geográfica de posição representada por este estado. Essa região brasileira teria um papel fundamental para a construção e consolidação das vias de comunicação nacionais que conduziria o contato entre as diferentes regiões do país e, consequentemente, entre os países da América do Sul.

É nesse quadro que nos acostumamos a encarar a importância geográfica de Mato Grosso.

Nessa moldura é que sobressai a importância do baixo relevo de seus pantanais, como do alto relevo da cinta de alturas que a Serra do Mar adianta até esses confins ocidentais de nosso territorio.

Mato Grosso é a superfície de contacto da civilização brasileira com o conjunto dos problemas de toda a sorte que se processam em torno de nossas fronteiras vivas do sudoeste. E o sul de Mato Grosso muito bem pode definir como a futura plataforma onde receberemos tudo que tivermos de carrear para Santos.

Nesse particular, o sector compreendido entre Corumbá, Campo Grande, e Ponta Porã há de ter, num futuro não remoto, a significação político-economica de uma Santos Mediterranea.

Em que pese todo o valor restante de Mato Grosso, o que é inconteste, seja pela exploração sistematica do manganez ou pelas jazidas de metais preciosos e lençóis petrolíferos, seja pela invasão do café paulista que marcha decididamente para nororeste, seja ainda pelo tesouro fantástico de sua vertente amazônica, o que não há duvida é que de sua posição geográfica emanará como entidade politica e economica.

E é tal a importância da posição geográfica de Mato Grosso, que só a partir do momento em que a politica nacional a tiver assimilado completamente começará Mato Grosso a representar o papel que lhe compete no cenário brasileiro e, por isto, no tablado continental.

E ha um fato, em aparência de caráter meramente econômico, mas que já está contribuindo para acelerar o surto político-economico de

${ }^{2}$ A análise geopolítica de Travassos é não apenas pioneira como original nesse tipo de discurso no país. Ao contrário dos demais do período, ela parte de uma minuciosa descrição das condições geográficas primárias do continente e do território brasileiro. Além disso, ele deriva daí um projeto geopolítico que está centrado não na unidade interna stricto sensu, mas na repercussão externa do movimento de integração interna, subordinando este àquele objetivo maior. Nesse sentido, na mais pura tradição inaugurada por Mackinder, Travassos empresta ao chamado "poder nacional" uma dimensão nova no contexto da geopolítica brasileira (COSTA, 2008, p.198-199). 
Mato Grosso. Esse fato é o desenvolvimento rápido do noroeste paulista invadido pelo cafesal e pelas manadas equinas de ricas fazendas criadoras, afora mil outras autações, gravitando todas em torno do potencial dos saltos do Avanhandava e de Itapura (TRAVASSOS, 1931, p.146-7, grifos do autor).

O território do Mato Grosso ganhou uma análise mais detalhada, demonstrando exatamente o papel desempenhado pela expansão dos rebanhos na região e, consequentemente do regime pastoril. Isso permitiu uma base suficiente para fazer as proposições sobre as vias de comunicação, sobretudo, a malha ferroviária, colocada como imprescindível ao desenvolvimento como também a segurança e a integração do território.

A província de Mato Grosso, colocada diante das regiões dominadas pelo elemento hispânico, sofreria as consequencias do desequilíbrio proveniente das diferenças entre a formação brasileira e a dos países vizinhos, todos vinculados àquela origem. Quando o Brasil já se apresentava com uma organização política bem delineada, com a articulação territorial embrionaria mas posta a salvo das crises dissociadoras agudas, as nações oriundas da colonização espanhola atravessavam ainda a inquietação de formações dispersivas e desencontradas. Não se haviam fixado na sua amplitude territorial. Não haviam articulado ainda os seus processos de produção com a organização politica correspondente.

A tais acontecimentos e prenúncios devia juntar-se o aparecimento de nova força, a jogar no tablado complexo em que a resultante retardava o seu aparecimento. O declínio da mineração devia conduzir ao abandono das rotas abertas pelos paulistas na sua arremetida para o Oeste. Esses itinerarios gigantescos ficariam esquecidos e relegados ao desaparecimento. Não mais seriam percorridos por levas humanas. Por eles não transitaria mais a serie de agrupamentos que devia fixar-se no interior, na condensação dos arraiais, à a beira dos rios, que eram os caminhos convidativos. (SODRÉ, 1941, p.50-1).

Assim, o problema do estabelecimento e consolidação das vias de comunicação no Brasil tornou-se essencialmente geográfico, ou seja, o estabelecimento de uma ligação coesa entre as regiões brasileiras que possibilitasse a unidade territorial advém de um conhecimento detalhado das condições naturais, políticas e econômicas do território. Percebe-se, nos excertos acima uma complementaridade entre os discursos de Nelson Werneck Sodré e Mário Travassos ${ }^{3}$.

3 "Seria demasiado insistir. Entretanto, é indispensavel fixar-se que a significação pratica das comunicações depende do sistema que realizam, inclusive pela variedade dos meios empregados, e das condições de traçado e trafego a que respondem. No ponto de vista relativo de nossas circunstancias essas razões assumem notavel gravidade por isso que muitos deixam a desejar as 
A preocupação era constante com a necessidade da integração entre as terras do Oeste brasileiro com a região denominada por Sodré de corpo nacional. A partir da instalação das vias de comunicação e da consequente ligação entre a área core de desenvolvimento econômico do país com a área que necessitava ser incorporada no processo de modernização, não se correria o risco de uma fragmentação territorial. De acordo com o autor, o Oeste não poderia ser ameaçado de ser retirado do resto da nacionalidade. Para isso, o desenvolvimento da malha ferroviária era condição imprescindível ao desenvolvimento econômico capitalista.

Dependendo da livre navegação do rio Paraguai e ligando-se ao resto do país por uma linha de comunicações tão perigosa e tão extensa, possuída, em seu trecho capital, por países de diretrizes diversas, a provincia de Mato Grosso não devia somente ser ameaçada, na sua integridade territorial, mas retardada, no seu progresso e divorciada, formalmente, do corpo nacional no qual jogava como um estranho apêndice, oscilante e contraditório, fraca e inerte, pronto a desarticular-se, pronto a entregar-se, constituindo-se, alem de tudo em ameaça para o resto da nacionalidade, como verdadeiro anteparo entre a atração espanhola e a atração lusitana, entra o imã das nações de origem hispânica e o Brasil, e como verdadeira linha de desarticulação entre as forças orientadas segundo a bacia platina e a bacia amazônica, aquela visceralmente anti-nacional e esta enfraquecida, como linha de junção - devendo resultar desses contrastes todos a mais pesada ameaça, que logo se remataria na guerra, solução transitória, com reflexos poderosos na colonização da região sul, onde se formariam focos de consolidação humana, instabilidade que seria resolvida, em última análise, nos tempos republicanos, com a construção da noroeste do Brasil e com a penetração das vias férreas do sistema paulista, buscando as barrancas do Paraná, na expansão cafeeira (SODRÉ, 1941, p.51-2).

O estado do Mato Grosso apareceu nos discursos dos geopolíticos das décadas de 1930 e 1940 como a região de principal destaque para as políticas territoriais do Estado brasileiro, bem como o principal estado para o qual a política continental seria direcionada.

Mato Grosso é assim a grande esquina de nosso territorio em pleno coração da massa continental, lá onde se cruzam os mais graves problemas decorrentes da competição entre o Prata e o Amazonas e onde o Atlantico encontra um dos mais profundos e acertados pontos de aplicação para seu antagonismo em relação ao Pacífico (TRAVASSOS, 1931, p.203).

nossas comunicações, seja como siste de forças a um tempo políticas, sociais e econômicas, seja pela precariedade dos traçados que adotamos ou do trafego que sobre estes mantemos" (TRAVASSOS, 1931, p.162). 
Não seria um "abandono" da área litorânea, mas a sua ligação com o interior do território colocando-o no alvo e na direção das políticas territoriais que foram aplicadas no período do Estado Getulista. O que fica evidente é esse discurso dos geopolíticos casados com a política da "Marcha para o Oeste".

Para Oeste! Não é precisamente voltar as costas para o mar e muito menos abrir luta contra o mar - por mais paradoxal que pareça é estreitar a aliança com o mar, ampliando terras a dentro a vinculação litorânea.

A faixa litorânea que articula o nosso hinterland com o mar deverá ser encarada com toda serenidade, para a escolha acertada dos pontos de partida do movimento político-economico-social para o Ocidente, tanto mais quanto é o Atlantico que banha as nossas costas, oceano que encarna a mais viva atração marítima após a descoberta do Novo Mundo. (TRAVASSOS, 1931, p.212-13).

Para Oeste! tem toda a concisão das verdadeiras formulas políticas. Quer dizer antes de tudo compreensão e definição do fácies geografico do Continente e do Brasil. Em seguida, comunicações, colonização, atividade industrial. Por sua vez, nesses desdobramentos se encontram outros aspectos, ligados à escolha dos meios de transporte, às questões de saneamento e educação, à noção de ordem, de urgência dos cometimentos.

Para Oeste! como formula politica de alto coturno, deve ser encarada como a resultante de um sistema de forças, como a direção geral de inúmeras atuações que visem simultaneamente a solução dos mais graves problemas nacionais e a consecução do papel funcional que o espaço e a posição geografica do Brasil lhe outorgam no continente e para além mar. (TRAVASSOS, 1931, p.214).

Em relação à construção da malha ferroviária como um projeto de modernização e integração do território tem-se as seguintes considerações. Vencovski (2006) demonstra que a prioridade econômica das ferrovias no período 1835-1957 era a exportação. Outro fator importante mostrado por esse autor é a relação entre a expansão agrícola e as ferrovias, sendo que, o sentido de expansão das ferrovias acompanhava as linhas de expansão da agricultura. Ligado a essas atividades que desencadearam com a instalação das ferrovias, Castilho (2017, p.70) enquadra as redes ferroviárias construídas em escala nacional como os "meios estratégicos para o funcionamento do território". Segundo o autor, entre a segunda metade do século XIX e início do século XX, as redes ferroviárias se apresentaram como os "principais meios de circulação de bens, produtos e pessoas nos eixos do interior para o litoral", o que pode ser traduzido, no discurso de Nelson Werneck Sodré, um escoamento de produtos do oeste ou desertão para o corpo da pátria. 
A partir do quadro de Vencovsky (2006) (quadro 1), pode-se depreender que Sodré escreveu o "Oeste" num momento em que o Estado brasileiro estava implementando a infraestrutura projetada, sobretudo as vias de transportes, mais especificamente a malha ferroviária.

Isso significa que a função principal da rede de transportes no final do século XIX e início do século XX era possibilitar o escoamento de produtos do interior do país (provenientes da agropecuária e do extrativismo) para as regiões litorâneas, onde estavam os portos que os exportariam para a Europa. Isso caracterizou um padrão espacial dos transportes no sentido oeste-leste, formando sistemas ferroviários isolados. (CASTILHO, D, 2017, p.70-71).

Nelson Werneck Sodré no seu papel de intelectual, geopolítico e militar, propunha um plano viário, no período Vargas, que acompanhasse "as linhas naturais ou geográficas de circulação do próprio território contendo as adaptações ou variantes que as possibilidades humanas põem hoje ao serviço dos homens de Estado". (TRAVASSOS, M. 1931, p.186). Essas linhas naturais ou geográficas de circulação acompanhavam, em verdade, a expansão agrícola sobre o território, conforme pode-se acompanhar pelo quadro de Vencovsky.

De acordo com Golbery de Couto e Silva (1952-60), leitor de Mário Travassos e de Nelson Werneck Sodré, entre o final do século XIX e início do XX do ponto de vista da circulação, o território brasileiro era um grande "arquipélago", formado por um núcleo central - São Paulo, Rio de Janeiro, Belo Horizonte -, três grandes penínsulas - região Nordeste, Sul e Centro-Oeste - e uma grande "ilha perdida" - A ilha amazônica. Neste sentido, Couto e Silva propõe um processo de ligação entre o núcleo central e as três penínsulas e, a partir disso, a ligação do Centro-Oeste com a Amazônia.

Sodré, no "Oeste", discute especificamente o papel da ferrovia que ligaria, neste caso, a "Estrutura brasileira/Corpo do Brasil" ("núcleo central" para Couto e Silva) ao "Oeste" ("península Centro-Oeste" para Couto e Silva).

Essa discussão está intrinsecamente envolvida com o processo de regionalização do território brasileiro, política territorial também iniciada durante a Era Vargas. A centralização do poder, o fortalecimento do Exército ${ }^{4}$ (instituição na qual Sodré atuava), a criação do IBGE (Instituto Brasileiro de Geografia e Estatística) e o projeto de unidade nacional e integração territorial, que estavam presentes como discurso e como prática do Estado, influenciaram diretamente Sodré nas projeções para o Estado envolvendo a região Oeste, ou também o grande interior brasileiro (Mato Grosso). Pode-se afirmar isso diante da possibilidade do livro Oeste ter sido um estudo encomendado pelo Estado com o

4 "O fortalecimento das Forças Armadas, especialmente do Exército, foi uma das características mais importantes dos anos 1930-1945. Ele se deu tanto em número de efetivos quanto em reequipamento e posições de prestígio". (FAUSTO, B. 2008, p.358). 
objetivo de se ter um levantamento sobre as potencialidades da região Oeste do Brasil. O Exército, no início do XX e em períodos precedentes, fazia várias incursões no território com diferentes objetivos e, Sodré, estava numa dessas incursões na década de 1930 quando o Oeste foi escrito.

Quadro 01: Periodização das Ferrovias no Brasil

\begin{tabular}{|c|c|c|c|}
\hline Caracteristicas Momento & $\begin{array}{l}\text { Criação e } \\
\text { expansão }\end{array}$ & $\begin{array}{l}\text { Estatização e } \\
\text { readequação }\end{array}$ & $\begin{array}{l}\text { Desestatização e } \\
\text { recuperação }\end{array}$ \\
\hline Periodo aproximado & $1835-1957$ & $1957-1996$ & 1996-atual \\
\hline $\begin{array}{l}\text { Plano nacional do governo } \\
\text { brasileiro relativo aos transportes }\end{array}$ & Ocupação & $\begin{array}{c}\text { Modernização do } \\
\text { território, "era } \\
\text { desenvolvimentista", } \\
\text { segurança nacional }\end{array}$ & $\begin{array}{c}\text { Inserção } \\
\text { internacional, } \\
\text { "globalização", } \\
\text { ocupação dos } \\
\text { cerrados }\end{array}$ \\
\hline $\begin{array}{l}\text { Caracteristica do sistema } \\
\text { ferroviário }\end{array}$ & Desenvolvimento & Readequação & Reestruturação \\
\hline Extensão da linha (Km) & $30 \mathrm{mil}$ & $30 \mathrm{mil}$ & $29 \mathrm{mil}$ \\
\hline Prioridade econômica do governo & Exportação & $\begin{array}{l}\text { Integração do } \\
\text { território/exportação }\end{array}$ & Exportação \\
\hline Controle das ferrovias & Privado & Estatal & Privado \\
\hline Investimentos em novas linhas & Privado & Estatal & Estatal/Privado \\
\hline Investimentos na operação & Privado & Estatal & Privado \\
\hline $\begin{array}{l}\text { Caracteristicas dos principais } \\
\text { fluxos }\end{array}$ & $\begin{array}{c}\text { Vários produtos e } \\
\text { passageiros }\end{array}$ & $\begin{array}{c}\text { Commodities e } \\
\text { passageiros }\end{array}$ & $\begin{array}{l}\text { Commodities } e \\
\text { containers }\end{array}$ \\
\hline Principais produtos & Café & Minério & Minério e soja \\
\hline $\begin{array}{l}\text { Prioridade dos investimentos em } \\
\text { transporte }\end{array}$ & ferrovias & rodovias & ferrovias e rodovias \\
\hline Objetivos dos investimentos & $\begin{array}{l}\text { Construção de } \\
\text { novas linhas }\end{array}$ & $\begin{array}{c}\text { Saneamento das } \\
\text { empresas }\end{array}$ & $\begin{array}{l}\text { Melhoria da } \\
\text { eficiência } \\
\text { operacional }\end{array}$ \\
\hline $\begin{array}{l}\text { Relação entre expansão agricola e } \\
\text { ferrovias }\end{array}$ & $\begin{array}{c}\text { A agricultura } \\
\text { segue a expansão } \\
\text { das linhas }\end{array}$ & - & $\begin{array}{c}\text { As ferrovias seguem } \\
\text { a expansão da } \\
\text { agricultura }\end{array}$ \\
\hline
\end{tabular}

Fonte: Vencovsky (2006, p.16) 
No primeiro momento da obra, Sodré destaca a necessidade de resolver um "problema geográfico" de primeira ordem em relação ao Oeste: a criação do vínculo entre os territórios de Mato Grosso ("o grande Oeste") ao "Corpo do Brasil".

A necessidade, vislumbrada pela clarividencia de Rio Branco, da ligação ferroviaria com a Bolivia, cortando as terras do Oeste, devia contribuir para a abertura e realização, embora retardada, de uma obra singular, que constituiria uma nova componente na geografia humana do Oeste, a estrada de ferro que, partindo de Baurú, no Estado de São Paulo e transpondo o vale do Paraná, chegou à barranca do Paraguai, devendo prolongar-se, através do vale deste último, rumo Corumbá, para atingir, com a parte boliviana, a cidade de Santa Cruz de La Sierra. A Noroeste do Brasil vinha resolver um problema geográfico de primeira ordem, em relação ao Oeste: contituiria o vínculo, ainda bem tenue, é verdade, que uniria os territorios matogrossenses ao corpo do Brasil [...]. (SODRÉ, 1941, p.111).

Sodré coloca a construção da ferrovia Noroeste do Brasil como uma obra de suma importância para o desenvolvimento paulista chegar até o interior do país. A ferrovia seria o símbolo e, ao mesmo tempo, a possibilidade da chegada do nível de desenvolvimento experimentado por São Paulo ao interior, funcionando como uma canalizadora do fluxo de modernização.

A possibilidade de integração do Oeste na comunidade nacional só foi viavel depois que a Noroeste reuniu a ponta dos seus trilhos, articulandose com os da Sorocabana, que poderia continuar o escoamento da produção central, levando-a a Santos, por obra da realização formidavel de Gaspar Ricardo, com o desvio de Mairinque, ou pela estrada estrangeira que une o porto às terras altas de Jundiaí.

O fato do centro de gravidade da extensa linha da Noroeste permanecer bem internado em territorio paulista, onde as cidades por ela servidas continuam num ritmo sempre acelerado de desenvolvimento, não deixa de traduzir as possibilidades do deslocamento progressivo desse ponto vital para as terras de Mato Grosso, no prolongamento da atividade paulista, já canalizada pela via ferrea para o centro do Brasil. (SODRÉ, 1941, p.111-2).

A ligação com a Bolívia a partir da construção da ferrovia Noroeste do Brasil pelas terras a oeste, reforça as ligações discursivas entre Sodré e Travassos. De acordo com Vlach $(2002 / 2003)$ :

Interessado na análise das relações entre a Geografia e a Política, Travassos aponta a existência de territórios marcados pelo que denomina de instabilidade geográfica. Define esse fenômeno como a "oscilação de certos territórios entre determinadas características que os circulam" (Travassos, 1935:61). As "características que os circundam" decorrem das condições 
geográficas, e da política definida por um Estado nacional face aos vizinhos.

A Bolívia, dividida entre a necessidade de um porto no Pacífico e outro no Atlântico, é um exemplo de instabilidade geográfica que, em caso de um conflito armado, provocaria problemas nas relações entre Brasil e Argentina, uma vez que esses Estados disputavam a hegemonia na América do Sul. (VLACH, 2002/2003, p.138-9).

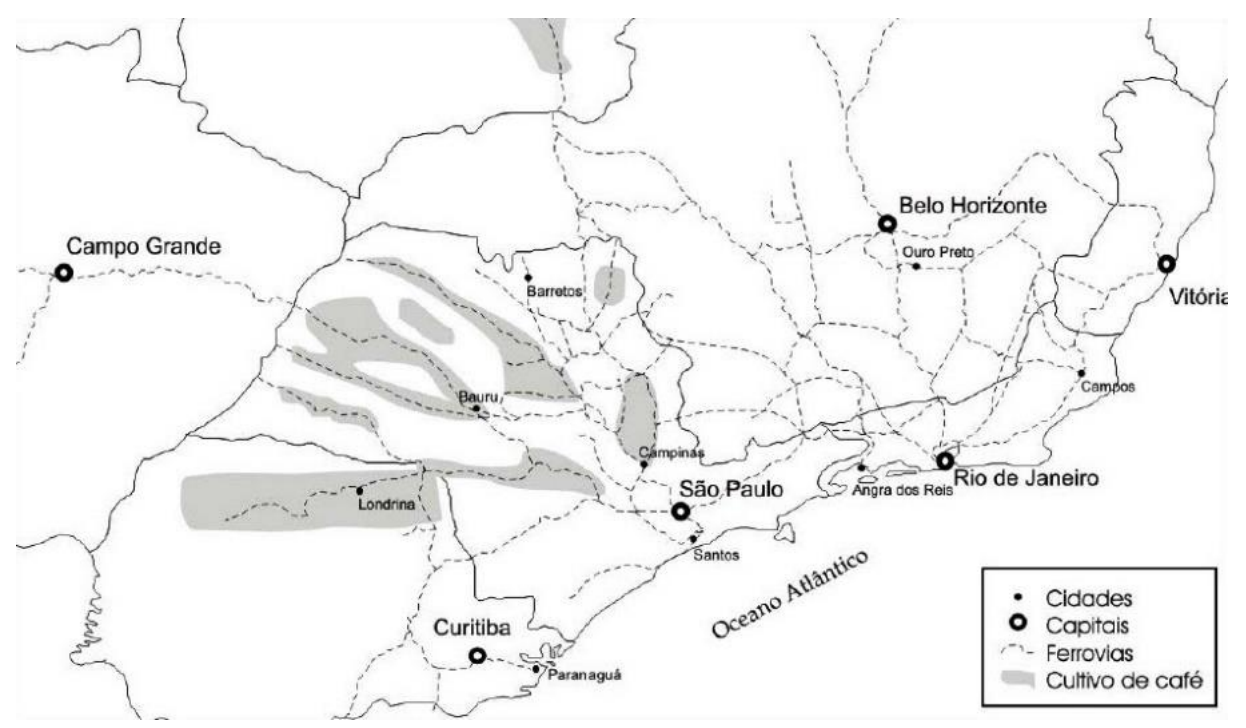

Figura 01: Ferrovias e o Café: Momento 1 Fonte: MONBEIG (1971, p.120)

Nelson Werneck Sodré também destaca a possibilidade de escoamento da produção pastoril para o mercado paulista pela via férrea.

A característica inicial e auspiciosa da via ferrea em questão, ao lado do vínculo que estabelecia entre o Oeste e a estrutura brasileira, da qual ele estava praticamente divorciado, foi a possibilidade do escoamento da produção pastoril daqueles rincões, trazendo-a ao mercado consumidor, cada vez mais denso, do Estado cafeeiro.

Articulando uma zona de dominio exclusivamente pastoril ao territorio em que o esforço humano, no nosso país, conseguiu constituir o mais alto dos padrões de cultura agrícola, a via ferrea da Noroeste operava um trabalho único e de importancia capital. (SODRÉ, 1941, p.112).

Percebe-se neste sentido, no discurso do autor, a ligação existente entre a construção das vias férreas acompanhando o desenvolvimento das lavouras, sobretudo as 
lavouras de café em São Paulo. O esboço cartográfico “A região vital do Brasil”, retirado do livro de Monbeig "O Brasil" (1971), ilustra esta situação.

A via férrea, desde o momento da construção, viria transformar o panorama das terras do interior. Sodré demonstra as modificações em prol do desenvolvimento, sobretudo, o econômico, que provocaria a construção da ferrovia que se transformaria na via do desenvolvimento do Oeste brasileiro.

Desde o inicio, desde a sua abertura ao tráfego, a via ferrea, mudando consideravelmente o panorama das terras interiores, exerceria uma poderosa ação na expansão humana no Oeste. Através da sua linha, penetraria essa zona uma crescente leva de trabalhadores. Cidades apagadas e mortas, tomariam novo impulso vivificador, ao contacto vigoroso do tráfego ferroviario. Ao longo do extenso prolongamento desses trilhos, nucleos urbanos se formariam ou assumiriam desenvolvimento até então desconhecido. Com a passagem dos anos, operado notavel deslocamento na geografia humana do Oeste, os grandes centros de condensação e de distribuição ficariam à beira da Noroeste. Campo Grande tomaria um impulso poderoso. Colocar-se-ia, na configuração geográfica alterada pelo ritmo da locomotiva, como centro distribuidor de primeira ordem, destinado a ampliar cada vez mais o seu raio de ação e a constituir-se em fulcro de todas as forças em jogo nos territorios do Oeste. (SODRÉ, 1941, p.112-3).

No excerto, Campo Grande, capital atual do estado do Mato Grosso do Sul, experimentaria um processo de desenvolvimento econômico e social possibilitado pela instalação da ferrovia. Ela se colocaria como a receptora e distribuidora dos recursos, ou da produção, advinda do centro econômico do país (São Paulo). Assim, Nelson Werneck Sodré coloca como consequência da construção da via férrea a condensação do "elemento humano" em terras do Oeste.

Como a gente de escassa civilização encontra sempre notavel facilidade em transmigrar, é possivel que a via ferrea, pela necessidade mesma de, por ela, escoar a produção pastoril, exerça uma poderosa ação imantadora sobre os agrupamentos de população do sul, fazendo-os gravitar para a sua esfera de ação e conduzindo mesmo a um largo movimento humano para os seus pontos mais sensiveis, em detrimento da região anteriormente dominante, nesse fascinio. Os centros à beira da Noroeste tomarão, muito cedo, um desenvolvimento muito grande, chamando a si todo o excesso humano, toda a massa oscilante que permanece no nomadismo das pastagens. Se tal ação for acompanhada pelo acesso progressivo da cultura agrícola, não é dificil prever a fixação desses elementos para um futuro não muito remoto. Tal função social, se levada a termo, será de efeitos sensiveis na organização social do Oeste pastoril, progressivamente podado em suas características. (SODRÉ, 1941, p.125). 
A via férrea é mostrada como a força - "a força que chegou para jogar no panorama do Oeste" - transformadora e definitiva para as terras do interior. A via férrea conseguiria incorporar essas terras dentro do sentido nacional, pertencentes ao corpo da nação.

A via ferrea estabeleceria o elo imprescindivel articulando a região do Oeste ao corpo nacional. Quebraria o perigoso divorcio que vinha na tradição histórica, imposto pelas eventualidades imperativas da configuração geral da geografia americana. Aproximando a região pastoril do mercado consumidor constituido em São Paulo, pelo adensamento de população que a lavoura cafeeira aí proporcionara e fornecendo o transporte, em troca, do parque industrial paulista ao sertão matogrossense, dos artigos necessarios à vida e ao conforto, a via ferrea estabeleceria o mais forte laço de união, desde que o apoiaria na reciprocidade de interesses econômicos. (SODRÉ, 1941, p.151).

O sentido nacional que a construção da via férrea apresentou para o Brasil, no discurso de Sodré, é evidente. Assim, a Noroeste do Brasil, que atravessaria todo o território brasileiro e que adentraria os territórios dos países vizinhos, constituiria, sem dúvida, não somente o sentido nacional brasileiro, mas, também uma influência imperialista. A proposição dessa infraestrutura se apresenta com o mesmo caráter proposto por Mário Travassos. Segundo Vlach (2002/2003)

No contexto de disputa da hegemonia na América do Sul, Travassos não ignora que a argentina, melhor estruturada economicamente, possui outras vantagens importantes em relação ao Brasil, dentre as quais a rede de transportes. Porém, considerando a dimensão e o "tipo continental" do território brasileiro, e que a "influência continental do Brasil" pode aumentar por intermédio de uma rede de transportes bem estruturada, e empregando todos os tipos de transporte - fluvial na bacia do Amazonas, ferroviário e fluvial na bacia do Prata [mesma proposta de Sodré], aéreo na extensão do território -, considera que o Brasil deve desenvolver uma política de transportes coerente com a sua ambição de exercer influência política na região. Trata-se, em suas palavras, de "um dever político" do Brasil; esse dever considera seus interesses em escala nacional e regional. (VLACH, 2002/2003, p.139-140).

Quanto à região amazônica, Sodré a propõe como uma faixa. Em Couto e Silva aparece como uma ilha: isolada do restante da economia e vida nacional. Nesta proposição, vê-se a região amazônica como uma ilha, ou seja, uma área ainda não ligada ao restante do território, mas, que se transformaria através da possível ligação entre o "Centro-Oeste" com o "Núcleo Central", a alternativa de dar início a um processo de integração efetiva do território com essas três regiões. Essa região, para Sodré, havia apresentado um surto de desenvolvimento econômico efêmero ("fulgurante, porém transitório"), durante o período da extração da borracha, no final do século XIX. 
Pelas peculiaridades a que ficou subordinada, dependendo mais da atração do Amazonas do que da que provinha do sul e do centro-sul, tal região se alterou sensivelmente, não viu o aparecimento de centros urbanos, que tivessem uma continuidade apreciavel, que tivessem vida, função propria. A faixa ligada à bacia amazônica permanece à espera do momento em que venha a exercer uma função de importancia. (SODRÉ, 1941, p.122).

Esse discurso dos militares de cunho geopolítico apresentou um substrato importante que teve na ciência geográfica a sua sustentação. Mário Travassos (1931), como uma figura importante dentro do Exército naquele período e representante dessa instituição, apresentou um discurso sobre a importância da Geografia para compreender e empreender uma análise sobre o território bem como projetar algo para o mesmo. Segundo ele,

sem espírito geografico não é possível a apreensão judiciosa dos problemas de governo, pelo menos modernamente. A sciencia geografica se desdobra de tal modo que se adapta a todas as múltiplas fórmas das atividades humanas. Assim como sempre se disse a química está presente em todas as manifestações da vida, pose-se agora dizer que a ciencia geografica se encontra no substratum de todos os problemas politicos e sociais.

As denominações dadas aos desdobramentos da ciencia geografica geografia, física, humana, economica, militar, politica, etc. - estão mesmo a indicar a notavel capacidade de adaptação da mais geral das ciencias à complexidade da vida moderna (TRAVASSOS, 1931, p.205-6).

Esse geopolítico apresentou argumentos sobre a importância de se utilizar da ciência geográfica para compor analises e projetos para o território brasileiro. Sabendo da sua atuação por dentro das instituições de ensino do Exército pode-se compreender o aparecimento da Geografia como disciplina nos currículos de formação dos oficiais do Exército. Tal como Travassos, Nelson Werneck Sodré teve, na ciência geográfica, a base de construção dos seus discursos, sobretudo, àqueles que apresentaram e apresentam uma relação direta com as práticas do Estado. Assim, destaca-se a importância do surgimento do conhecimento/ciência geográfica nos currículos das escolas militares, influenciando diretamente o discurso daqueles que irão, junto às classes dominantes, projetar o país. Neste sentido, Geografia e Política aparecem juntas influenciando decisivamente na formação territorial do Brasil.

\section{Considerações Finais}

Analisar e revisitar as obras de Nelson Werneck Sodré na atualidade significa a possibilidade de entender de que forma o espaço brasileiro foi pensado e organizado materialmente por alguns grupos das classes dominantes pertencentes a sociedade brasileira.

Nos finais do século XX e início do XXI tem-se uma bibliografia especializada que buscou analisar a obra de Sodré por dentro da ciência histórica, da Sociologia e da 
Ciência Política. Esta bibliografia especializada analisou temáticas que apareceram nas obras de Nelson Werneck Sodré no seu período marxista, tais como: democracia, modo de produção, colonização, revolução burguesa e política.

O discurso apresentado é decisivo no sentido de deslindar questões cruciais para a compreensão de como se deu a formação territorial brasileira. Sua contribuição revela que o progresso material esteve à frente dos impactos sociais que os projetos envolvidos no ordenamento proposto poderiam trazer. Em verdade, tanto a natureza como as populações presentes nas áreas destino dos mesmos não foram consideradas senão como recursos de ordem econômica passíveis de serem convertidas aos propósitos das classes detentoras do poder.

A "leitura" sobre o espaço brasileiro apresentada por Sodré esteve, indiscutivelmente, ligada às orientações específicas dos geopolíticos brasileiros, sobretudo os militares, baseada na consolidação territorial, na unidade e identidade nacional e na unidade territorial.

A "visão de mundo" de Nelson Werneck Sodré esteve calcada sobre um tripé: unidade nacional, identidade nacional e unidade territorial. Foi com essa "visão de mundo" que Sodré aproximou-se terminantemente do discurso promovido pelo Estado Getulista, como é demonstrado suscintamente neste trabalho.

\section{Referências}

ANDRADE, M.C de. Geopolitica do Brasil. São Paulo: Editora Ática, 1993.

ANSELMO, R.C.M.S. Oliveira Vianna e a Unidade -Identidade do Espaço Brasileiro. 1995. 142 f. Dissertação de Mestrado (Área de concentração em Organização do Espaço) - Instituto de Geociências e Ciências Exatas, Universidade Estadual Paulista, Rio Claro, 1995.

CASTILHO, D. Modernização territorial e redes técnicas em Goiás. 2a Edição. Goiânia: Editora UFG, 2017.

COSTA, W.M. Geografia Política e Geopolítica: Discursos sobre o território e o poder. $2^{\mathrm{a}}$ edição. São Paulo: Editora da Universidade de São Paulo, 2008.

FAUSTO, B. História do Brasil. 13ª ed. São Paulo: Editora da Universidade de São Paulo, 2008. - (Didática, 1).

MELLO, L.I.A. A Geopolítica do Brasil e a Bacia do Prata. Tese de Doutorado - Universidade de São Paulo, FFLCH - USP, 1987.

MOORE JUNIOR, B. As origens sociais da Ditadura e da Democracia: Senhores e camponeses na construção do mundo moderno. Lisboa: Edições Cosmos - Martins Fontes, 1967.

SODRÉ, N.W. Oeste: Ensaio sobre a grande propriedade pastoril. $1^{\text {a }}$ Ed. Rio de Janeiro: Ed. José Olympio, 1941. 
SODRÉ, N.W. Panorama do Segundo Império. 1 ${ }^{a}$ Ed. Rio de Janeiro: Ed. José Olympio, 1939.

TRAVASSOS. M. Projeção Continental do Brasil. Rio de Janeiro: Companhia Editora Nacional, 1931.

VENKOVSKY, V.P. Sistema Ferroviário e o Uso do Território Brasileiro: Uma análise do movimento dos produtos agrícolas. 2006. 150 f. Dissertação (Mestrado Geografia) - Instituto de Geociências, Universidade Estadual de Campinas, Campinas, 2006.

VLACH, V.R.F. Estudo Preliminar acerca dos Geopolíticos Militares brasileiros. Terra Brasilis, Rio de Janeiro: Grupo de Trabalho de História do Pensamento Geográfico no Brasil, no $4 / 5$, p.137-159, 2002/2003.

\footnotetext{
Marco Túlio Martins

Pussui graduação, mestrado e doutorado em Geografia pela Universidade Federal de Uberlândia. É pesquisador do Núcleo de Pesquisa em Geografia e Memória da UFU. Atualmente é professor da Universidade Estadual de Goiás - Campus Itapuranga, onde atua como Coordenador do Curso de Geografia da UEG - campus Itapuranga.

Endereço: Av. Rio Araguaia esq c/ Av. Rio Paranaíba s/n, setor Miltom Faria, Itapuranga (GO). CEP 76.680.000.

E-mail: marcogeografia2008@yahoo.com.br
}

\section{Rita de Cássia Martins de Souza}

Possui mestrado em Geografia pela Universidade Estadual Paulista Júlio de Mesquita Filho e doutorado em Geografia (Organizacao do Espaco) pela Universidade Estadual Paulista Júlio de Mesquita Filho. Atualmente é Professora Associado 2 da Universidade Federal de Uberlândia.

Endereço: Instituto de Geografia - UFU. Campus Santa Mônica - Bloco 1H. Av. João Naves de Ávila, 2121 - Bairro Santa Mônica. Uberlândia - MG - CEP 38400-902.

E-mail: ritacmsou@gmail.com 